Dans, Noemi. El riesgo país en la inversión extranjera directa: concepto y modalidades de riesgo.

\title{
EL RIESGO PAÍS EN LA INVERSIÓN EXTRANJERA DIRECTA: CONCEPTO Y MODALIDADES DE RIESGO
}

\section{THE COUNTRY RISK IN FOREIGN DIRECT INVESTMENT: CONCEPT AND CATEGORIES OF RISKS.}

\author{
NOEMI DANS RODRÍGUEZ ${ }^{1}$ \\ Profesora colaboradora \\ Universidad Complutense de Madrid \\ Profesora de Economía y Relaciones Internacionales \\ Universidad Europea de Madrid \\ noemidans@gmail.com
}

Fecha recepción: septiembre de 2012

Fecha aceptación: diciembre de 2012

\section{RESUMEN}

El análisis de riesgo país en la exportación se basa en el estudio de la capacidad de pago y en las pérdidas que puedan ocasionar al acreedor un deterioro de ésta. En cambio, el riesgo país en la inversión directa está relacionado con los eventos que pueden producir pérdidas derivadas de incumplimientos contractuales, minoración de los derechos de propiedad, daños en los activos o cese de actividades. Habida cuenta de que las operaciones de inversión extranjera directa son de naturaleza distinta a las exportaciones, este trabajo aborda el concepto del riesgo país en unas y otras con el fin de conocer cuales son los riesgos comunes y cuales son específicos de cada tipo de operación.

PALABRAS CLAVE: Inversión extranjera directa, multinacionales, riesgo país, riesgo político.

\section{ABSTRACT}

The assessment of country risk in exports is based on the analysis of the capacity of payment and the eventual losses for the creditor. The country risk in foreign direct investment is, instead, related to the events that can produce losses as a consequence of breach of contracts, deprivation of property rights, damage to assets or cessation of activities. Considering that characteristics of exports and foreign direct investment are different, this paper presents an analysis of the concept and the scope of country risk in both operations in order to know which categories of risk are shared and which categories are specific.

KEYWORDS: Foreign direct investment, multinational firms, country risk, political risk.

JEL: F23

\footnotetext{
${ }^{1}$ Agradezco a Ángel Vilariño sus comentarios y sus inestimables aportaciones a este trabajo. 
Dans, Noemi. El riesgo país en la inversión extranjera directa: concepto y modalidades de riesgo.

\section{INTRODUCCIÓN}

Los riesgos a los que se enfrenta una empresa a la hora de abordar un proyecto de inversión extranjera directa (IED) se pueden dividir en dos categorías: aquellos que surgen como resultado de su propia gestión en un determinado país y aquellos que surgen de la esfera política y macroeconómica de ese país. Los primeros son los riesgos comerciales y dependen fundamentalmente del grado de eficiencia en la dirección del proyecto. Los segundos entran dentro de la categoría de riesgo país.

"La gestión del riesgo país tiene una particular relevancia en la economía del desarrollo y en la política de cooperación debido a que puede alterar tanto el comportamiento de la inversión internacional como la política de los gobiernos de los países receptores. Es conveniente, por lo tanto, alcanzar un alto grado de conocimiento de este tipo de riesgo para intentar optimizar su gestión". Esta afirmación realizada en Gordon (2008) sirve de base para la introducción de este trabajo en el que buscamos identificar las modalidades de riesgo país que pueden afectar a la IED ${ }^{2}$. Las características y las circunstancias económicas, políticas y sociales de un país son factores que pueden provocar una pérdida económica a los inversores extranjeros. Ahora bien, ¿de qué manera se pueden originar esas pérdidas?, ¿qué aspectos constituyen posibles eventos de riesgo? El objetivo de este trabajo es averiguar qué aspectos y características de un país pueden originar situaciones de riesgo para el inversor directo. Para ello, tomaremos como punto de partida los eventos de riesgo que pueden originar situaciones de riesgo para el exportador.

En este trabajo realizamos un estudio comparado de este tipo de riesgos basándonos en la literatura, y no en datos, con el fin de obtener un mapa conceptual del riesgo y de la incertidumbre que los inversores perciben en el entorno económico y sociopolítico del país receptor de la IED, frente a los que percibe el exportador. Este análisis pretende ser útil tanto para la toma de decisiones de los inversores como para el país receptor, cuya estrategia de desarrollo podría estar condicionada por la actitud inversora internacional.

La valoración del riesgo país en el comercio internacional se basa en el estudio de la capacidad de pago. En cambio, en las operaciones de IED los riesgos están relacionados con las pérdidas que pueden producir al inversor a través de daños en los activos o en la actividad que desarrolle en el país receptor de la inversión. La IED y las exportaciones son operaciones de naturaleza distinta y esto hace que la posible pérdida económica adquiera también una forma distinta. Debido a estas

${ }^{2}$ La definición de Mossa (2002) de inversión extranjera directa es el proceso por el cual residentes de
un país adquieren la propiedad de unos activos en otro país con el objeto de controlar la producción
y/o distribución y otras actividades realizadas por estos. El FMI, en su Manual de Balanza de Pagos
define la IED como "una inversión que se hace con el propósito de adquirir un interés duradero en
una empresa que opera en una economía distinta de la suya, siendo el interés del inversor el de tener
voz en la gestión de la firma. Por su parte, la UNCTAD en el World Investment Report define la IED
como una inversión que implica una relación a largo plazo y representa unos intereses duraderos en
una empresa residente en una economía distinta de la del inversor. En estas definiciones hay dos
aspectos que caracterizan a la IED: la duración larga y el control en la gestión. Así pues, para el
propósito de este trabajo, consideraremos inversión directa como el proceso de creación o de
adquisición de activos, excluyendo la inversión en cartera, con el propósito de desarrollar a largo
plazo una actividad de la que se tiene el control en la gestión
Papeles de Europa 25 (2012): 109-129

Doi: http://dx.doi.org/10.5209/rev_PADE.2012.n25.41100 
Dans, Noemi. El riesgo país en la inversión extranjera directa: concepto y modalidades de riesgo.

diferencias es pertinente preguntarse si el riesgo país al que están expuestas unas en una economía coincide o no con el que puede afectar a las otras en esa misma economía ${ }^{3}$.

Para responder a esta pregunta, la primera cuestión es profundizar en el conocimiento del riesgo país, en su concepto. A ello dedicamos el apartado siguiente de este trabajo. A continuación, identificamos cuáles son los eventos que generan las distintas modalidades de riesgo país en la IED. Esto nos permitirá ir identificando simultáneamente cuales de esas modalidades coinciden con las modalidades de riesgo país que afectan al comercio exterior.

\section{EL CONCEPTO DE RIESGO PAÍS}

Hablar de un asunto complejo como el riesgo país exige especificar antes con precisión qué queremos decir cuando decimos riesgo. En economía el concepto de riesgo está ligado al de pérdida, y la medida del riesgo a la cuantificación de la pérdida. Holton (2004) se refiere a la definición de riesgo de Knight (2006) como la más famosa y quizá sea la que sienta las bases de buena parte de los conceptos en los que luego profundizan otros autores. Este autor hace que el concepto pivote sobre la capacidad de medir y distingue entre riesgo, o incertidumbre cuantificable mediante un cálculo de probabilidad objetiva que se puede realizar a priori, e incertidumbre propiamente dicha, que no se puede medir porque lleva implícita una probabilidad que en este caso es subjetiva porque está influida por juicios. Esta probabilidad subjetiva está relacionada únicamente con el grado de desconocimiento, ya sea por un desconocimiento inherente al evento, es decir intrínseco a su naturaleza, o motivado por la ignorancia del analista sobre el mismo. Desde ese mismo punto de vista subjetivo, Vilariño (2001) plantea un paso más en la conceptualización del riesgo definiéndolo como "las pérdidas potenciales por encima de un resultado esperado" lo cual supone que el riesgo no implica simplemente la obtención de pérdidas sino que éstas superen a la pérdida esperada. También el concepto de riesgo de Markovitz (1952) lleva implícito el retorno esperado. Este aspecto obliga a definir a priori el retorno deseable para poder medir el riesgo con base en las desviaciones que se produzcan ${ }^{4}$. Su procedimiento para valorar el riesgo combina el uso de técnicas estadísticas y "el juicio de hombres prácticos". Esta participación del análisis cualitativo y humano en el método de valoración es el reflejo del carácter subjetivo del riesgo.

Además de la incertidumbre o el desconocimiento, la exposición es un segundo factor importante asociado al riesgo y analizado también en Holton (2004). Una cosa es que no tengamos certeza sobre un evento y otra distinta es que su acontecimiento nos importe de alguna manera. Así pues, el grado de incertidumbre

\footnotetext{
${ }^{3}$ Qué duda cabe que una comparación con el riesgo país en los mercados financieros sería también pertinente. Sin embargo, los mercados financieros internacionales no son objeto de este estudio. Se trata de un riesgo que afecta sólo a los países que tienen acceso a estos mercados, un número de países inferior al que nos ocupa, que son los que participan en la globalización como receptores de IED y como importadores en el comercio mundial. Los países importadores y receptores de IED, en mayor o menor medida, son, en definitiva, la práctica totalidad de los países en desarrollo.

${ }^{4}$ Markowitz (1952) calificó a las desviaciones como indeseables, frente al retorno deseable o esperado, y relacionó de manera implícita las desviaciones con el riesgo pero no se refirió a éstas expresamente como un término equivalente al riesgo. 
Dans, Noemi. El riesgo país en la inversión extranjera directa: concepto y modalidades de riesgo.

de un sujeto sobre un evento, el desconocimiento sobre si ocurrirá o no, no tiene por qué estar asociado al grado de exposición de ese sujeto a ese evento, al grado en el que le afectaría que el evento ocurriera. Es más, ambas, incertidumbre y exposición, abarcan un ámbito mayor que el que podemos realmente percibir. El sujeto expuesto a un acontecimiento incierto no conoce el grado en el que está realmente expuesto ni es consciente del grado de incertidumbre que rodea a ese evento. Por esta razón Holton (2004) introduce en el concepto de riesgo la limitación de la percepción definiendo la probabilidad como la cuantificación de la incertidumbre percibida y la exposición como el grado de afectación que percibimos. El riesgo es lo que percibimos que desconocemos y la exposición, lo que percibimos que nos importa ese desconocimiento, es decir, el valor de la inversión que está sometida a la probabilidad o a la incertidumbre de sufrir una eventual pérdida. Esta visión de Holton (2004) conecta con la taxonomía del conocimiento de Gomory (1995). El conocimiento se deriva de las mediciones y las teorías, es decir de la capacidad de hacer mediciones sobre aquello que queremos conocer y de la existencia de teorías que permitan interpretar esas mediciones. En virtud de las primeras, un evento es conocido si sus resultados se conocen y su probabilidad se puede estimar, siendo también posible contrastar la validez de esa estimación. Obsérvese que esta definición de lo conocido coincide con la definición de riesgo de Knight (2006). En cambio, un evento es desconocido si no se le puede asignar una probabilidad a cada uno de sus resultados a pesar de que estos se conocen; se trataría de una incertidumbre cuyo riesgo no puede identificarse ex ante. Por último, los eventos que no se pueden identificar son incognoscibles ${ }^{5}$ y entran en la categoría de ignorancias. Atendiendo a la capacidad de las teorías para generar conocimiento, Gomory (1995) establece que lo conocido tiene su base en un paradigma mientras que lo desconocido se refiere a conjeturas que se basan en modelos que no llegan a ser paradigmas, es decir situaciones que generan un riesgo epistémico derivado del conocimiento imperfecto del evento. Finalmente, lo incognoscible son situaciones que no se explican mediante ningún modelo con credibilidad científica. Hasta que se desarrolle un modelo adecuado estas situaciones son incomprensibles, como ocurrió durante varios años con los agujeros negros del espacio.

Podemos acudir a una perspectiva más para avanzar en la creación de un marco que nos permita delimitar bien el concepto de riesgo. La perspectiva operativa puede servir de nexo entre todo lo anterior y el análisis empírico, pues establece que un concepto, en nuestro caso el riesgo, es el conjunto de operaciones que lo caracterizan. La corriente operativista fue introducida por el premio Nobel de física, Percy Bridgman, en 1927 en su obra La Lógica de la Física Moderna. Bridgman (1959) recoge que el conocimiento se deriva de las experiencias y que sólo podemos definir un concepto como el conjunto de operaciones en los que ese concepto se manifiesta, o a través de las cuales lo experimentamos. Es evidente que, desde este punto de vista, lo que no se percibe no se puede definir. Así pues, operativamente sólo podemos aspirar a trabajar con el riesgo percibido, teniendo siempre presente que estamos dejando de abarcar un componente del riesgo que no es perceptible, no es definible y no es medible. De todo ello se deriva que es estéril preguntarnos si una determinada valoración del riesgo mide el riesgo porque stricto sensu no es factible. Al hablar de valoración del riesgo nuestra tarea será averiguar

\footnotetext{
${ }^{5}$ Unknowable en el original.

Papeles de Europa

25 (2012): 109-129
} 
Dans, Noemi. El riesgo país en la inversión extranjera directa: concepto y modalidades de riesgo.

si una valoración logra medir el riesgo percibido de una manera que resulte sencillamente útil para mejorar su manejo.

En economía las contingencias no son previsibles, lo cual, por otro lado, no quiere decir que no podamos acotarlas o que no podamos delimitar los contornos de los fenómenos que las ocasionan. Volviendo a la definición de Knight (2006) y atendiendo a su concepto de riesgo, al hablar de riesgo debemos considerar también la probabilidad subjetiva o la incertidumbre inherente a algunos riesgos de la esfera de las ciencias sociales. Éstos tienen un comportamiento inexacto, al estar influido por interpretaciones y por juicios. Por lo tanto, si queremos abarcar la mayor parte del riesgo en nuestro análisis debemos aspirar a incluir también las incertidumbres. Esto es especialmente significativo en las ciencias sociales y más concretamente en el análisis del riesgo país, cuyos componentes son, como luego se verá, factores económicos, políticos y sociales. Quizá las definiciones que mejor reflejan todo este pensamiento son la de David James (2004): "El riesgo político es humano, subjetivo, severo e impredecible"; y la de Vilariño (2001), "El riesgo es un concepto difícil, escurridizo, que se resiste a ser encerrado en modelos formales (...). No es sorprendente esta dificultad si pensamos que detrás de los riesgos se encuentra toda la complejidad de la realidad económica y financiera". En este análisis y en las conclusiones que de él obtenemos tenemos presente estas limitaciones.

Con base en todo lo anterior, el marco teórico más adecuado para nuestro estudio del riesgo país en la IED debe tener un enfoque operativo y una visión subjetiva del riesgo. Además, estamos analizando posibles pérdidas que se derivan de eventos protagonizados por el hombre y por la sociedad. Esto requiere algo más que modelos econométricos. Requiere una interpretación de los eventos, realizada por conocedores expertos de las consecuencias que de ellos se han derivado a lo largo de la geografía y de la historia. Es necesaria, por lo tanto, una valoración cualitativa que contribuya a determinar el ámbito y el grado de incidencia de los fenómenos en las posibles desviaciones en la previsión de pérdidas económicas.

Nuestro análisis se fundamenta también en la aportación de Holton (2004) sobre la percepción. Esto tiene que ser necesariamente así porque los aspectos políticos, sociales y económicos son en buena parte desconocidos, pues a menudo no existe ni base empírica suficiente para asignar una probabilidad ni paradigmas que permitan interpretarlos con rigor científico. Incluso existe un componente incognoscible en cuanto que, hoy por hoy, ignoramos aspectos que pueden constituir en el futuro eventos de riesgo aún no identificados. Así pues, este trabajo se basa en los riesgos país que percibimos para cada tipo de operación.

Hasta ahora nos hemos referido al riesgo país pero a menudo se utilizan los términos riesgo país y riesgo político indistintamente, tanto en la literatura académica como en el sector inversor y asegurador. Ambos conceptos son distintos y diferentes también del riesgo soberano. Empecemos por este último, que se refiere a la exposición a una pérdida en operaciones transnacionales con el Estado o con el sector público de un país y está asociado a una eventual posición deudora de este (Moosa 2002, Simon 1992). Así entendido, el riesgo soberano no existe en la IED. No obstante, volveremos a él más adelante para plantear que se trata de un riesgo 
Dans, Noemi. El riesgo país en la inversión extranjera directa: concepto y modalidades de riesgo.

de alcance mayor que el que proponen estos dos autores y para comprobar que sí existe una vertiente de riesgo soberano que afecta a la IED.

El riesgo país es un concepto mucho más amplio. Según Moosa (2002) se define como "exposición a una pérdida económica en operaciones transnacionales causada por eventos producidos en un determinado país que están, al menos en cierto modo, bajo el control de gobierno". Ahora bien, estos eventos pueden ser de carácter económico, como una inflación galopante, un deterioro del déficit de cuenta corriente de balanza de pagos o un sobreendeudamiento externo, o bien de carácter político, como la inseguridad jurídica o los cambios normativos. Pero incluso los eventos de carácter económico, por ejemplo la quiebra de una empresa por falta de financiación bancaria o por una caída acusada del consumo, son consecuencia directa de la gestión de las autoridades económicas del país. Así pues, ambos aspectos, económicos y políticos, tienen su origen último en la política, de ahí que utilicemos la expresión riesgo político para referirnos al riesgo país.

El término político es quizá más sencillo de precisar que el de riesgo. Por político podemos referirnos a las personas que intervienen en las cosas del gobierno y en los asuntos de Estado y también a la actividad de quienes rigen los asuntos públicos. Qué duda cabe que la actividad política puede estar en ocasiones influida por determinados grupos sociales que intervienen en los asuntos públicos con sus acciones y con sus opiniones. Así pues, el riesgo político se origina en las decisiones de los gobernantes. Ahora bien, entre los agentes que pueden influir en éstas tenemos a los colectivos que puedan aspirar a sustituirlos y a los ciudadanos que pueden influir en la gestión de los primeros y de los segundos. A esta lista cabe añadir al propio inversor, pues en ocasiones las causas que generan la pérdida se derivan de comportamientos o decisiones sociopolíticas cuyo origen está en la actitud o la gestión de éste en el país. Son los casos en los que los eventos de riesgo surgen como respuesta a los efectos de la inversión extranjera, u originados por esta última.

En definitiva, los agentes que pueden originar riesgo político en la IED en un determinado país son los gobernantes, los que aspiran a sustituirlos, algunos grupos sociales con capacidad para influir en la gestión del gobierno y el propio inversor.

\section{EL RIESGO PAÍS EN LA INVERSIÓN EXTRANJERA DIRECTA}

Como se ha señalado antes, cualesquiera que sean sus causas, el riesgo en economía tiene como consecuencia una pérdida. En el riesgo de crédito ${ }^{6}$ la pérdida se deriva del impago de una deuda. Un exportador, un tenedor de bonos soberanos o corporativos o un banco financiador están todos expuestos a un mismo riesgo, el

\footnotetext{
${ }^{6}$ Vilariño (2001) define el riesgo de crédito como la posibilidad de sufrir una pérdida originada por el incumplimiento de las obligaciones contractuales de pago y especifica sus causas: retroceso en la solvencia de los prestatarios relacionado con problemas de liquidez, pérdidas continuadas e incluso quiebra en el caso de empresas, o por disminución de los ingresos en las familias, aunque también puede producirse por ausencia de voluntad de pago. Y añade: "la modelización del riesgo de crédito ha evolucionado desde el planteamiento que consideraba únicamente como suceso desfavorable el incumplimiento del pago, a un enfoque más amplio, donde se contemplan otros sucesos relevantes como los cambios en la calidad de los agentes acreditados, aunque no se produzca el incumplimiento". 
Dans, Noemi. El riesgo país en la inversión extranjera directa: concepto y modalidades de riesgo.

de impago. Así pues, no ha lugar un debate sobre la forma cómo el riesgo país afecta al comercio o a la inversión financiera. En cambio, el inversor directo puede ver materializada su pérdida de diversas maneras. Un daño en los activos instalados en el país o la paralización de las actividades serían dos ejemplos. No es preciso que se produzca un cese completo de las actividades. Se dan casos en los que acontecimientos como rescisión de contratos, recortes en el suministro de energía, racionamiento de insumos locales o reducción de tarifas del servicio que la empresa proporciona provocan un recorte en la actividad que se refleja en un deterioro en la cuenta de resultados. Algunos autores como Meldrum (2000) y Herberg (2002) incluyen entre las consecuencias del riesgo país en la IED la pérdida de rentabilidad mientras que Simon (1992) se refiere exclusivamente a la pérdida derivada de la incapacidad para repatriar capitales, dividendos o beneficios. Por su parte, el Banco Mundial, a través de su Agencia Multilateral de Garantías para las Inversiones (MIGA por sus siglas en inglés), define el riesgo político como "riesgos asociados a las acciones del gobierno que 1) deniegan o restringen el derecho de un inversor o propietario a usar o beneficiarse de sus activos o 2) reducen el valor de la firma" (MIGA, 2011). En este trabajo consideramos como consecuencias del riesgo las pérdidas económicas derivadas de la incapacidad para transferir capitales al exterior ${ }^{7}$, del daño o la pérdida de valor en una parte o en la totalidad de los activos y del cese total o parcial de la actividad ${ }^{8}$.

Puesto que estamos considerando varias modalidades de pérdida, las mencionadas en el párrafo anterior, y varios aspectos que pueden generarla, económicos, políticos y sociales, es previsible que los eventos de riesgo país sean también diversos. Pero antes de identificarlos necesitamos tener presentes las características que queremos que cumplan para que adquieran esa categoría. El evento que ocasione una pérdida debe estar fuera del control del inversor, al igual que ocurre con todas las modalidades del riesgo, pues de otra manera cabría la posibilidad de actuar contra él. Por la misma razón, la probabilidad o la incertidumbre debe ser reducida, ya que de lo contrario se desarrollarían los factores necesarios para reducirla. Por último, su realización debería tener consecuencias severas o al menos suficientes para que su análisis, valoración y gestión sean pertinentes. Por otro lado, el carácter cambiante del riesgo nos obliga a observar los cambios que se van produciendo en las circunstancias que lo generan para valorar cómo éste va aumentando o disminuyendo, partiendo siempre de un nivel inicial de riesgo. Queremos darle al análisis un enfoque que podríamos llamar dinámico, de evolución del riesgo a partir de un nivel de riesgo inicial. Ahora bien, podemos considerar que hay riesgo en i) situaciones en las que el nivel de riesgo inicial no aumenta pero que ya comportan de por sí un nivel de riesgo no despreciable, ii) incrementos del riesgo frente al nivel inicial que provocan pérdidas al inversor o iii) incrementos del riesgo frente al nivel de partida que provocan unas pérdidas que son superiores a las previstas. Desde un punto de vista operativo, que es el que tomamos en este análisis pues es el punto de vista del inversor, lo más adecuado es optar por el último concepto. Así pues, serán riesgo país los eventos que provoquen pérdidas superiores a las que los inversores

\footnotetext{
${ }^{7}$ Generalmente, el inversor directo estará interesado en transferir al exterior, fundamentalmente repatriar, beneficios, dividendos y capitales desinvertidos.

${ }^{8} \mathrm{Si}$ este trabajo estuviera orientado a la actividad aseguradora estaríamos obligados a acotar con precisión el grado de paralización de la actividad y de reducción del valor de los activos a partir del cual consideramos materializada una pérdida. Como no es el caso, consideramos suficiente con delimitar el concepto de pérdida sin necesidad de tener en consideración su cuantía. 
Dans, Noemi. El riesgo país en la inversión extranjera directa: concepto y modalidades de riesgo.

prevén. El análisis del riesgo obliga a considerar la valoración de la situación inicial del riesgo, primero, y el deterioro que pueda sufrir, después, siendo riesgo stricto sensu sólo el deterioro más allá del previsto. Con esto no negamos la existencia de un riesgo en términos estáticos ni la existencia de un riesgo evolutivo. Ambos pueden ser considerables desde un punto de vista conceptual pero no para nuestro análisis, que es fundamentalmente operativo.

Si bien el concepto de riesgo país tiene muchas definiciones y genera bastante debate, hay un más que aceptable grado de consenso en cuanto a los eventos que provocan situaciones de riesgo. Y esto es así tanto en la literatura académica como en el mercado asegurador. Hemos comparado siete fuentes (ver Tabla 1 al final de este trabajo), siendo una de ellas la visión agregada de dieciséis compañías aseguradoras por cuenta de sendos Estados de países de la OCDE (ECAS o Export Credit Agencies, por su denominación en inglés) y otra la de MIGA. Una tercera fuente es la OCDE, otra es la visión de Iranzo (2008) publicada por el Banco de España, y el resto son autores académicos y en activo en empresas multinacionales. La tabla siguiente recoge los eventos que han identificado cada una de ellas. Todas las fuentes coinciden casi sin matices en los cuatro primeros eventos de la tabla. MIGA menciona junto con el riesgo de guerra y violencia política el terrorismo, aspecto que analizaremos más adelante. En cuanto a la actitud de los gobiernos, el quinto evento de la tabla, las fuentes incluyen aquí varias circunstancias en un mismo concepto, calificado por Meldrum (2000) como soberano, que en nuestra opinión merece una disección mayor. Por un lado están los cambios legislativos que un gobierno pueda introducir como parte de su política económica, industrial, de desarrollo, etc. Un ejemplo serían los cambios de los precios en servicios públicos, como electricidad. En estos casos el evento de riesgo puede afectar a empresas nacionales en la misma medida que a las extranjeras.

Por otro lado está el incumplimiento de compromisos contractuales asumidos en relación con una IED determinada. En esta categoría entrarían por ejemplo la restricción del acceso a materias primas locales, cortes en el suministro de energía o en el aprovisionamiento de agua o ruptura de licencias de explotación de recursos naturales que se habían firmado previamente. Es más, dentro de este capítulo de eventos se puede distinguir entre incumplimiento de compromisos generalizado o el que está dirigido a una determinada inversión de manera discriminada. El primero afectaría a toda la inversión extranjera en el país, sin hacer distinciones de país de origen o sector.

Otra cuestión mencionada expresamente por Herber (1992) como un evento específico en la IED y que Meldrum (2000) asocia al riesgo de transferencia es la voluntad de pago. No compartimos esta visión ya que en las operaciones de inversión directa el Estado no tiene una posición deudora con el inversor, salvo algunas excepciones circunstanciales como la adquisición de bienes o servicios, por ejemplo. Así pues, nosotros no consideramos el impago por parte del Estado como un evento relacionado con las operaciones de IED. Por lo tanto no lo tendremos en cuenta en este estudio.

En la tabla constan también elementos como la política económica, que incluiremos en el capítulo de cambios regulatorios; el riesgo económico, que en las operaciones de inversión directa sería la causa última de los riesgos de transferencia y de 
Dans, Noemi. El riesgo país en la inversión extranjera directa: concepto y modalidades de riesgo.

convertibilidad; y las relaciones bilaterales, que pueden influir en los riesgos soberano, de confiscación, expropiación y nacionalización y también de guerra. Por último, no cabe duda que variaciones acusadas e inesperadas en el tipo de cambio pueden provocar pérdidas considerables e imprevistas a la empresa extranjera, aunque se trate de un riesgo mencionado únicamente por Meldrum (2000).

Hemos establecido estas relaciones entre los eventos y las modalidades de riesgo que mencionan estos autores para poder agrupar los primeros e incluirlos de forma ordenada en la categoría del riesgo que provoca cada uno. Esta ordenación facilita el análisis comparativo que queremos realizar. Todo lo anterior nos permite delimitar seis categorías de riesgo país para la IED: i) el riesgo de transferencia, ii) el riesgo de imposibilidad de cambiar moneda o de "convertibilidad", iii) el riesgo de tipo de cambio, iv) el riesgo de confiscación, expropiación y nacionalización o riesgo "CEN", v) el riesgo de guerra, desestabilización sociopolítica o terrorismo y vi) el riesgo de incumplimiento de compromisos y de cambios regulatorios.

\section{i y ii) Riesgo de transferencia de capitales y riesgo de convertibilidad de divisas}

La convertibilidad es el cambio de moneda local a una moneda aceptada internacionalmente, realizado dentro de las fronteras del país que acoge la inversión, que sirva para transferir capitales al exterior. La transferencia es la posibilidad de transferir esa moneda al exterior. La empresa inversora puede estar interesada en transferir al exterior, generalmente repatriar, los capitales desinvertidos, los dividendos obtenidos en la gestión del negocio o la amortización de préstamos concedidos por un banco extranjero o de la matriz. Los riesgos se derivan de la falta de disponibilidad de divisas en la economía o de alguna razón de orden normativo que, habiendo adquirido la divisa, no permita su transferencia al exterior.

El origen de estos riesgos es, generalmente, de carácter económico y fundamentalmente, de balanza de pagos. El déficit de la cuenta corriente de la balanza de pagos coexiste a menudo con un nivel de endeudamiento en divisas elevado, combinación que genera un deterioro de estos riesgos. Se trata de una circunstancia que está fuera del control del sector privado y que afecta a la globalidad del país por encima de los intereses específicos de los distintos operadores económicos. De ahí que no haya dudas en clasificarlos como riesgo país. La limitación a la convertibilidad es el resultado de una cantidad de divisas insuficiente, es decir de una incapacidad de hecho de convertir moneda. Se trataría de un riesgo económico con un origen en la balanza de pagos y en el nivel de deuda en divisas. En este caso hablaríamos de un riesgo país de naturaleza más económica que política, con la salvedad a la que ya hemos aludido de que la causa última es la política económica ${ }^{9}$. En cambio, las restricciones a la transferencia son siempre una decisión política, una prohibición. Es más, si analizamos la causa que puede llevar a las autoridades a impedir la repatriación de capitales a los inversores extranjeros podríamos encontrar una razón sin ningún origen de orden económico. El riesgo de transferencia en la IED es un riesgo político puro.

\footnotetext{
${ }^{9}$ Si consideramos las operaciones de compra en las que el deudor es el sector público la salud de las cuentas públicas será otro indicador determinante en la estimación del riesgo de transferencia en el comercio internacional. 
Dans, Noemi. El riesgo país en la inversión extranjera directa: concepto y modalidades de riesgo.

Lo anterior sienta las bases preliminares para responder a nuestra pregunta sobre si los riesgos de transferencia y convertibilidad son iguales para inversores y exportadores. Sin embargo, podemos plantearnos un aspecto adicional y preguntarnos si el surgimiento de un riesgo de convertibilidad o de un riesgo de transferencia es consecuencia de la política económica del gobierno de un país o del orden financiero internacional. Se podría decir que parte del origen del problema está en el endeudamiento pero podríamos atribuirlo a la gestión pública sólo en tres casos: i) si toda la deuda fuese deuda pública, ii) si el sector financiero y todos los flujos de capitales de entrada y salida estuvieran en manos del sector público y iii) en el caso de que ambos estuviesen fuertemente regulados. No obstante, la experiencia muestra crisis financieras y de deuda que tienen lugar en un contexto mundial de liberalización de capitales y de desregulación impuestos a escala global. Estas medidas son ineludibles para la inmensa mayoría de países so pena de entrar en un enfrentamiento con los financiadores y los socios comerciales que tendría unos costes inasequibles para sus economías. ¿Es el gobierno el responsable de estas situaciones? ¿Lo son los bancos? ¿O lo son los organismos internacionales, a los que les correspondería regular la actividad financiera entre países o al menos dejar un mayor margen para las políticas económicas autóctonas? ¿Se trata de un riesgo circunscrito al ámbito del país o deberíamos hablar de un riesgo país global? Sin duda son cuestiones muy pertinentes que suscitan la idea de que los eventos de riesgo país son cambiantes en función de la evolución del contexto mundial y que los agentes que los generan están cambiando con motivo de la globalización. No vamos a tratar esta cuestión del cambio de riesgo país a riesgo país de globalización aquí pero podría ser objeto de otra investigación relacionada con esta.

\section{iii) Riesgo de cambio}

Las variaciones en los tipos de cambio de la moneda local frente al dólar o al euro pueden ser causa de pérdidas, o de ganancias, considerables para el inversor extranjero. El riesgo de cambio a corto plazo puede ser fácilmente cubierto con los mecanismos disponibles en el sistema financiero pero a largo plazo, que es el horizonte en el que opera la inversión directa, los seguros de cambio no son eficientes. Esto da lugar a otra modalidad más de riesgo país que afecta al inversor en cuanto a que puede restar valor a los beneficios, dividendos o capitales repatriados y al balance de la empresa, que deberá consolidarse con el de la matriz. Las fluctuaciones pueden estar motivadas por una decisión política de modificar el sistema cambiario, sustituyendo uno de tipos fijos por otro de bandas cambiarias con ajuste progresivo por ejemplo. También pueden estar motivadas por el propio mercado de divisas, en los casos de tipos de cambio libres. En el primer caso, el carácter político del riesgo es incuestionable mientras que en el segundo, el riesgo es el resultado del funcionamiento del mercado internacional de divisas y de capitales en el que pueden darse incluso ataques especulativos contra la moneda local. En cualquier caso, existen mecanismos en manos de las autoridades monetarias del país para esterilizar estos ataques. Así pues, consideramos el riesgo de tipo de cambio como un riesgo político, de política económica, sea cual sea el origen de las fluctuaciones. 
Dans, Noemi. El riesgo país en la inversión extranjera directa: concepto y modalidades de riesgo.

\section{iv) Riesgo de confiscación, expropiación y nacionalización (CEN)}

Las tres acciones gubernamentales, confiscación, expropiación y nacionalización, se refieren a acciones legales o administrativas que pueden producir una minoración en los derechos de propiedad o un cese de las actividades de la empresa. Esta es la razón por la que están en el mismo capítulo, aunque se trate de conceptos distintos que debemos diferenciar.

La expropiación es la transferencia de la titularidad de los activos que ejercen las autoridades del país receptor sobre la inversión directa y a favor del Estado en virtud de un derecho que les ha sido conferido por la justicia. El riesgo para el inversor radica bien en la no percepción de una indemnización económica o justiprecio o bien en la percepción de una indemnización injusta, inferior a la que correspondería legalmente.

Existe otro tipo de inferencia en los derechos del inversor que también constituye una forma de expropiación. Se trata de los actos desarrollados por los gobiernos del país receptor con intención de aumentar progresivamente el control sobre la inversión. Si bien estos actos no ocasionan un cese de actividades completo en un momento determinado, sí pueden causar una merma importante y progresiva de ingresos a lo largo de un período. Los cortes frecuentes de suministro eléctrico o el encarecimiento y la merma en el suministro de materias primas locales son dos ejemplos de estos actos que constituirían un riesgo.

La confiscación es una expropiación ilegal. En este caso las autoridades del país que ha acogido a la inversión no están ejerciendo un derecho conferido por Ley al transferir al Estado la titularidad de los activos.

La nacionalización consiste en la transferencia de la titularidad de las acciones de la empresa extranjera al Estado. Puede llevarse a cabo en términos de expropiación o de confiscación.

Los riesgos de Expropiación, Confiscación y Nacionalización no afectan a las operaciones comerciales, de manera que estamos ante una modalidad de riesgo específica de las inversiones directas.

\section{v) Riesgo de Guerra, desestabilización sociopolítica y terrorismo}

Aunque todo el mundo tiene en mente lo que es una guerra, cuando se trata de la causa de una pérdida económica es necesario ser exhaustivos en la definición y acotar el término. Una manera útil de hacerlo es partir de una interpretación amplia de las situaciones de guerra que incluya todas las posibles circunstancias que puedan ser consideradas como tal y determinar después cuáles de esas circunstancias deberían considerarse eventos de un riesgo político para la inversión directa. El objetivo es analizar el alcance y las motivaciones de la desestabilización del orden social. Así pues, en función del porcentaje de la población implicada y de las motivaciones, tenemos diferentes modalidades de desestabilización (Ibáñez, 2001) a las que nos referimos a continuación. 
Dans, Noemi. El riesgo país en la inversión extranjera directa: concepto y modalidades de riesgo.

La "guerra" es el conflicto armado entre dos o más naciones o entre bandos de una misma nación que utilizan la violencia para ganar el derecho a gobernar o a constituirse como Estado o a apropiarse de un recurso ajeno, como por ejemplo un territorio. Actualmente no se declara abiertamente la guerra de forma explícita y puede ocurrir, aunque parezca paradójico, que entre dos países enfrentados coexistan acciones violentas con algún modo de relación pacífica. India y Paquistán, Irán e Iraq, Israel y la franja de Gaza o Estados Unidos e Irán son ejemplos de deterioro en las relaciones entre países en los que no ha mediado una declaración formal de guerra pero sí se desarrollan actos hostiles suficientemente graves. Se trata de casos en los que permanecen abiertas las legaciones diplomáticas pero la tensión y la hostilidad entre ellos obliga a considerarlos dentro de esta categoría de riesgo.

Una "rebelión" es una revuelta contra el Estado que hace referencia a una actitud individual con connotaciones legales contempladas en el ordenamiento jurídico. Es importante incidir en el hecho de que la rebelión es una acción casi personal. Si adquiriera un carácter colectivo, entraríamos en la categoría de insurrección. La "insurrección" se define como el levantamiento o la rebelión colectiva de una nación o un pueblo. De nuevo, en este caso nos estamos refiriendo a la insurrección contra el poder político. Cuando se logra el objetivo político y tiene lugar, por ejemplo, un cambio en las Instituciones Públicas o un cambio de gobierno, el término entra en la categoría de "revolución". Las diferencias entre unos y otros se establecen en términos del grado de apoyo popular que representen, del carácter político de los objetivos que reivindiquen y del alcance de las acciones 0 , dicho de otra manera, de la consecución del objetivo. La protesta personal de un joven en Túnez que se quema a lo bonzo ante las dificultades económicas en diciembre de 2010 derivó en la revolución tunecina, en la huida del presidente Ben Alí, en la celebración de elecciones a una Asamblea Constituyente y en la designación del nuevo Presidente Marzouky un año después.

Este último ejemplo nos lleva a otras formas de desestabilización social, las que pueden llegar a generar las protestas de algunos sectores de la sociedad, como estudiantes, trabajadores 0 sindicatos. Este tipo de reivindicaciones no son estrictamente de carácter político sino que suelen estar relacionadas con las condiciones del mercado de trabajo y con la calidad de vida. Por esta razón no las consideramos eventos de riesgo país. Ahora bien, en algunos casos este tipo de protestas sí han llegado a evolucionar a estadios en los que sí han logrado modificar el programa político o incluso a derrocar gobiernos. Son los casos de Argentina o, mas recientemente, del ejemplo citado anteriormente de Túnez o en Egipto. Es difícil establecer la frontera entre lo que son manifestaciones públicas de un rechazo más o menos amplio a la gestión política y lo que se convierte en movimientos masivos con capacidad potencial para la desestabilización política o para la generación de pérdidas a la IED. En esa frontera es donde surge el riesgo país. En el caso del exportador, el riesgo se deriva del deterioro de la economía y, por ende, de la insolvencia que pueda provocar la desestabilización sociopolítica en general. En cambio, los movimientos sociales que generan un riesgo de pérdidas para el inversor extranjero son únicamente los que surgen con esa motivación específica. Están alentados por sentimientos nacionalistas o por un conflicto de intereses provocado por la actividad o por la actitud de los inversores en territorio extranjero. Las empresas tienen que ser conscientes de cómo sus prácticas pueden colisionar 
Dans, Noemi. El riesgo país en la inversión extranjera directa: concepto y modalidades de riesgo.

con los intereses de la sociedad en la que se han instalado. Desconocer estos hechos es un profundo error de gestión empresarial que cometen muchos inversores extranjeros en muchos países. En estos casos es en su propia actividad donde está el origen y la causa del riesgo.

Con el terrorismo cabe preguntarse en qué medida se puede o se debe tratar la combinación del componente político y el componente criminal. La actividad terrorista es una acción criminal penada por las leyes de casi todos los países. Las motivaciones suelen ser de índole religioso, ideológico o nacionalista. En última instancia, desembocan en reivindicaciones políticas que son las que acaban canalizando las protestas, dado el deber de la clase gobernante de gestionar de una u otra manera todas las cuestiones que suscitan las manifestaciones terroristas. Así pues, al igual que ocurre con los actos de desestabilización sociopolítica, los actos de terrorismo político son un evento de riesgo país en todas sus modalidades ${ }^{10}$ y serán un evento de riesgo país para la IED en la medida en que puedan provocar pérdidas al inversor. Se han dado casos en los que el inversor extranjero se ha visto obligado a gestionar el terrorismo, como el suministro de electricidad por Unión FENOSA en territorio paramilitar colombiano. En cualquier caso es importante especificar, en primer lugar, que el carácter o no de evento de riesgo país no está necesariamente relacionado con la dimensión de la acción o con la cuantía de lo daños que provoca. Estos aspectos son muy relevantes en todo caso. En segundo lugar, el reconocimiento del carácter político de una organización terrorista no debe abstraernos de su perfil criminal, que también la caracteriza.

La relación entre una desestabilización sociopolítica y un deterioro del crecimiento económico y de la capacidad de pago de un país es una cuestión ampliamente debatida en la literatura académica, pero su análisis en profundidad no es el objetivo de este trabajo. Sí nos interesa, en cambio, delimitar la forma como el riesgo de guerra, terrorismo o las diferentes formas de desestabilización sociopolítica puede afectar a la inversión directa y compararlas con la forma como puede afectar a la solvencia.

Un contexto económico caracterizado por la dependencia de los recursos naturales del país y en el que la gestión es deficiente o denunciable según el criterio de los ciudadanos genera un riesgo elevado de desestabilización sociopolítica o violencia política $^{11}$. Ross (2004) analiza catorce modelos econométricos y varios estudios cualitativos sobre la relación entre abundancia de recursos naturales y guerra civil llegando a cuatro conclusiones singulares: (1) La dependencia del petróleo genera un riesgo alto de violencia política pero no de una duración larga del conflicto. El tipo de violencia más frecuente en estos casos, y quizá también en los casos de dependencia de otros recursos, es tensiones secesionistas. (2) La abundancia de gemas, opio, coca y cannabis provocan un riesgo de alargamiento de los conflictos preexistentes, pero no de su inicio. (3) No hay base empírica ni estadística suficiente

\footnotetext{
${ }^{10}$ Nótese que nos referimos al terrorismo político. Es importante precisar que un acto terrorista de violencia común puede tener consecuencias sociales graves, con un coste elevado en vidas humanas como el que protagonizó una secta en Oklahoma (EEUU) con cerca de 300 muertos, y sin embargo no constituir un acto de violencia política incluido en la categoría de riesgo país por no tener objetivos políticos.

${ }^{11}$ De nuevo nos referimos a las acciones de violencia con objetivos políticos frente a las de violencia criminal.
}

Papeles de Europa

25 (2012): 109-129

Doi: http://dx.doi.org/10.5209/rev_PADE.2012.n25.41100 
Dans, Noemi. El riesgo país en la inversión extranjera directa: concepto y modalidades de riesgo.

sobre el efecto de abundancia de bienes agrícolas, más allá de los estupefacientes. (4) la tesis de la elevada relación entre materias primas y guerra no es robusta.

La Tabla 2 nos muestra algunos países africanos ricos en recursos minerales que han sufrido conflictos secesionistas. El análisis de Ross (2004) parte de una situación en la que el control de los recursos está en manos del Estado. Nosotros podemos extrapolar las conclusiones a una situación en la que las licencias de explotación estén concedidas a inversores extranjeros en los términos en los que el Estado, propietario de los recursos, haya estipulado. Salvando las diferencias, la extrapolación es válida para lo que nos ocupa, que es establecer una relación entre una gestión de los recursos naturales del país percibida como ineficiente por los ciudadanos y el riesgo de violencia política encaminada a alterar la titularidad de la explotación de los recursos.

Tabla 2. Recursos minerales y conflictos secesionistas en África.

\begin{tabular}{llll}
\hline Country & Region & Duration & Resources \\
\hline Angola & Cabinda & $1975-$ & Oil \\
Burma & Hill tribes & $1949-$ & Tin, gems \\
Democratic Republic of Congo & Katanga/Shaba & $1960-65$ & Copper \\
Indonesia & West Papua & $1969-$ & Copper, gold \\
Indonesia & Aceh & $1975-$ & Natural gas \\
Morocco & West Sahara & $1975-88$ & Phosphates, oil \\
Nigeria & Biafra & $1967-70$ & Oil \\
Papua New Guinea & Bougainville & $1988-$ & Copper, gold \\
Sudan & South & $1983-$ & Oil \\
\hline
\end{tabular}

Fuente: Ross (2004)

La violencia política no requiere que se desarrollen situaciones de violencia propiamente dicha. Simon (1989) acuña el término revoluciones sin guerrillas para referirse a la inestabilidad política provocada por conflictos de baja intensidad pero con una implicación mayoritaria por parte de los ciudadanos que están originados por fuerzas políticas, sociales, económicas y étnico religiosas o por una combinación de todas ellas. Se trata de movimientos fundamentalmente urbanos y repentinos. Sólo dos semanas bastaron para derrocar el régimen de Ferdinand Marcos en Filipinas en 1986 a manos del "poder el pueblo". La revolución islámica en Irán en 1979 y la breve duración del gobierno posterior de Shapur Bakhtar, la salida de Haití de Duvalier y la inestabilidad social con el presidente posterior, Henry Namphy, o la reciente primavera árabe y la desestabilización que aún persisten en Egipto o Siria son varios ejemplos de este fenómeno. Podemos decir que las causas más frecuentes son:

i) políticas de austeridad extrema en contextos de crisis económicas acusadas, como en la primavera árabe

ii) cuestionamiento de la legitimidad de los gobiernos en regímenes autoritarios, como el de Pinochet en Chile, el de Noriega en Panamá, el del Sha de Irán o el de Chun en Corea del Sur

iii) nacionalismos y sentimientos étnico religiosos, como en Sudáfrica, en el Estado de Punjab en la India o en Palestina. 
Dans, Noemi. El riesgo país en la inversión extranjera directa: concepto y modalidades de riesgo.

En definitiva, el contexto genera mayor riesgo cuanta mayor es la distancia entre las aspiraciones del pueblo y lo que éste puede conseguir. Es decir, el riesgo es mayor cuanto mayor sea la incapacidad del sistema para acomodar las demandas de determinados grupos sociales, más o menos numerosos, organizados y poderosos.

Es interesante la comparación que hace Simon (1989) entre las guerrillas características de Colombia, Palestina o algunos países africanos y las revoluciones sin guerrillas. Según este autor, estas últimas se diferencian de las primeras en que i) pueden coger desprevenidos incluso a las propias guerrillas, como ocurrió con los sandinistas ante las revueltas por el asesinato del líder opositor Pedro Joaquín Chamorro en 1978, ii) pueden lograr resultados que las guerrillas no han logrado gracias a su capacidad de expansión y rapidez, iii) actúan sin violencia, iv) suelen ser menos ideológicas y están enfocadas a objetivos más concretos que reúnen un consenso y un ánimo de reivindicación mayor entre la población y v) el período posterior al cambio conseguido suele ser muy inestable.

Los llamados Estados fallidos son otra causa de riesgo de guerra o de inestabilidad sociopolítica. En sus obras El Principe y La Política como vocación, Nicolás Maquiavelo y Max Weber, respectivamente, se referían al Estado como el ente que ostenta el uso legítimo de la fuerza dentro de un territorio. Una definición más conciliadora proporcionan Thomas Hobbes en su Leviatán y Jean Jacques Rousseau en el Contrato Social, según la cual los ciudadanos y los estados pactan la pérdida de libertad a cambio de seguridad. Con base en una teoría del Estado más desarrollada, podemos decir que el Estado falla cuando pierde la capacidad para desarrollar las funciones que tiene atribuidas. Estas funciones son la seguridad, la calidad de las instituciones, el control de las fronteras, la provisión de infraestructuras y servicios sociales, la regulación económica y la participación política. La capacidad de los Estados para desarrollar cada una de estas funciones no es uniforme. Colombia es un ejemplo de gestión macroeconómica, sobre todo para los estándares latinoamericanos, pero es un caso de fracaso en la gestión de la seguridad. Di John (2011) establece una relación directa entre Estado fallido, en cualesquiera de sus cometidos, y violencia política. Putzel (2005) califica de Estados frágiles a los países que estudia en el Centro de Investigación de Estados en Crisis de la London School of Economics, que son países de renta baja que sufren un alto grado de presión. La OCDE (OECD/DAC, 2008) define Estados frágiles como los que "carecen de la capacidad o voluntad para proporcionar las funciones básicas necesarias para reducir la pobreza, favorecer el desarrollo y salvaguardar la seguridad de su población". Hyden et al. (2011), del Banco Mundial, se refiere a los que "afrontan desafíos severos tales como instituciones débiles, gobernabilidad débil, inestabilidad política y violencia frecuente".

Todos estos factores, gestión de los recursos, necesidades sociales insatisfechas y Estados débiles, están entre las causas del riesgo de guerra y de desestabilización sociopolítica. Se trata de aspectos que están presentes en las dos vertientes del análisis del riesgo país pero es posible que el riesgo que suscitan varíe. Ya hemos visto algunas cuestiones preliminares que sugieren diferencias claras en la incidencia de este tipo de riesgo en cada tipo de operación pero en el apartado siguiente llegaremos a conclusiones sobre este aspecto. 
Dans, Noemi. El riesgo país en la inversión extranjera directa: concepto y modalidades de riesgo.

En cuanto al terrorismo, puede afectar tanto a la capacidad de pago de un país como a los intereses de las empresas extranjeras que operan en él. Colombia es un ejemplo paradigmático de cómo el terrorismo merma la actividad económica y por ende, la capacidad de crecimiento y de desarrollo de un país. Y qué duda cabe que una acción terrorista puede afectar de una manera más directa a una empresa extranjera, bien provocando daños en los activos o bien provocando pérdidas económicas a través de la extorsión, por ejemplo.

\section{vi) Riesgo de incumplimiento de compromisos y de cambios en la regulación ó} Riesgo de ejercicio de la soberanía

El riesgo de incumplimiento de compromisos se refiere a los compromisos explícitos pactados contractualmente entre el inversor y las autoridades del país receptor. Evidentemente, el incumplimiento puede venir por cualquiera de las dos partes, inversor o gobierno, y ambos tienen efectos negativos sobre la contraparte. El análisis de los efectos del incumplimiento de los compromisos asumidos por el inversor extranjero sobre el país receptor es otro estudio sin duda interesante. Sin embargo, el que nos importa en éste es el incumplimiento contractual del gobierno del país receptor y su efecto en la empresa extranjera.

El incumplimiento de los compromisos asumidos por el gobierno en relación con una inversión extranjera es una decisión soberana. La soberanía es la cualidad del soberano, y es el soberano quien ejerce la autoridad suprema del poder político. Esto implica que no existe en un país un poder superior a la soberanía. Cuando se trata de riesgo, este aspecto es importante pues del hecho de que no exista un poder superior al soberano se deriva la circunstancia de que tampoco existe, más allá de los convenios regulados por el Derecho Internacional, ningún recurso contra sus acciones. Naturalmente, como resultado de lo anterior, un aspecto importante en la definición y percepción del riesgo soberano se desprende de quién sea el soberano de un país y eso depende del régimen político del que se trate. El ejercicio de la soberanía se manifiesta de manera muy diferente en regímenes absolutistas de tipo monárquico o de tipo republicano o en regímenes democráticos en los que la soberanía reside en el pueblo. En este caso, los depositarios de la soberanía son los representantes elegidos por el pueblo quienes la ejercerán en virtud de su criterio y de sus capacidades, y también en este caso la ejercerán sin ningún poder superior que los limite. Existen hoy por hoy países que aún carecen de los elementos básicos propios de una democracia e incluso democracias llamadas maduras que legitiman un poder que se torna casi absolutista. El instrumento soberano por excelencia es la ley y la aplicación de una ley puede tener consecuencias económicas considerables.

Se trata, por lo tanto, de un riesgo país de dimensiones impredecibles que deberá ser gestionado por exportadores y por inversores, pero ¿cómo afecta a unos y a otros?

Como hemos mencionado anteriormente, algunos autores como Moosa (2002) y Simon (1992) entienden por riesgo soberano el riesgo de impago en las operaciones en las que el comprador o el deudor es de carácter público, fundamentalmente el Estado. En estos casos el riesgo soberano engloba tanto la incapacidad como la falta de voluntad para el pago por parte de un gobierno. Ahora bien, yéndonos al lado del inversor directo, los incumplimientos de compromisos contractuales 
Dans, Noemi. El riesgo país en la inversión extranjera directa: concepto y modalidades de riesgo.

asumidos por el Estado y los cambios normativos o legislativos implican el uso de la capacidad soberana para decidir en un sentido u otro. Es evidente que estaríamos hablando de la actitud de un gobierno que es el resultado directo del ejercicio de su soberanía. Podemos decir que el incumplimiento de contratos y los cambios regulatorios son un riesgo de ejercicio de la soberanía que en este trabajo, de cara al análisis comparativo que nos ocupa, contrastaremos con el riesgo soberano de falta de voluntad de pago de la deuda por importaciones.

La dinámica cambiante puede hacer también que en el futuro desaparezca la percepción de algunas de estas categorías de riesgo e incluso que aparezcan otras nuevas. Pensemos, por ejemplo, en el interés de un inversor por construir un complejo hotelero en las Islas Marshall. En una valoración del riesgo país al que puede estar expuesto, encontramos que estas islas están en peligro desde que la posibilidad de un aumento en el nivel del mar está ganando peso entre la comunidad científica internacional. Hay muchas islas en el océano Pacífico que podrían sumergirse si esto se confirmara. Así pues, las cuestiones medioambientales podrían convertirse en uno de los aspectos que hay que analizar relacionados con los proyectos de inversiones. También pueden generar riesgos nuevos las tecnologías de la información y la comunicación y el uso que se haga de ellas para provocar daños en los sistemas informáticos de gobiernos, instituciones o empresas. En este sentido, se especula sobre un ataque con virus troyanos contra los sistemas de las instalaciones nucleares en Irán y sobre la caída de internet en Estonia durante tres semanas en abril de 2008, que afectó a los sistemas de algunas Instituciones, periódicos y bancos y que fue provocada como respuesta a la retirada de un monumento a la memoria de la guerra soviética. Estos daños pueden suponer una pérdida económica en sí mismos o pueden generar desestabilización política que dé lugar a una pérdida. La compañía aseguradora británica Lloyd's contempla el surgimiento de este tipo de riesgos entre las modalidades de riesgo país en su Memoria de 2010 (Lloyd's, 2011), y ya en Vilariño (2001) se describe el riesgo tecnológico como integrante de los riesgos operativos, es decir, como cualquier discrepancia que presente una operación económica o financiera entre "lo que debería ser y lo que realmente es". Este riesgo abarca tanto errores como intencionalidad.

\section{CONCLUSIONES}

La definición del concepto y la delimitación del alcance de los riesgos políticos a los que se expone la inversión extranjera directa pueden hacerse mediante un análisis comparado con los riesgos que inciden en el comercio internacional. Estos últimos han sido más analizados por la literatura académica y empresarial y se tiene mayor experiencia sobre ellos.

Este análisis comparado nos lleva a identificar seis modalidades de riesgo en la IED: i) el riesgo de transferencia; ii) el riesgo de imposibilidad de convertir moneda o de "convertibilidad"; iii) el riesgo de tipo de cambio; iv) el riesgo de confiscación, expropiación y nacionalización o riesgo CEN; v) el riesgo de guerra, desestabilización sociopolítica o terrorismo; y vi) el riesgo de incumplimiento de compromisos y de cambios en la regulación o de ejercicio de la soberanía. 
Dans, Noemi. El riesgo país en la inversión extranjera directa: concepto y modalidades de riesgo.

Así pues, para establecer las similitudes y diferencias en la percepción del riesgo país en el comercio y en la IED, y para valorar en qué medida es válido para la segunda el análisis del primero, es preciso analizar los siguientes riesgos:

- Riesgo de transferencia

- Riesgo de convertibilidad

- Riesgo de cambio

- Riesgo de guerra y violencia política

- Riesgo de ejercicio de la soberanía.

Para estos riesgos comunes a ambos tipos de operaciones, será necesario identificar si existen diferencias en el mismo tipo de riesgo por el hecho de estar asociado a operaciones de naturaleza distinta. En caso afirmativo, será necesario determinar cuales son las diferencias. Debemos plantearnos si una restricción a la salida de capitales puede afectar en mayor o menor medida al pago por importaciones que a la repatriación de dividendos. También es pertinente preguntarse si la disponibilidad de divisa en el sistema financiero local es la misma para los importadores que para los inversores o si una desestabilización sociopolítica puede suponer una probabilidad de pérdida mayor para unos y para otros. Estas diferencias, es decir, el análisis de los mismos riesgos desde dos primas diferentes, deberá ser objeto de otra investigación que tome como punto de partida el hecho de que se trata de riesgos comunes.

En cambio, el riesgo de confiscación, expropiación y nacionalización no existe como tal en las exportaciones y por lo tanto no procede incluirlo en el análisis comparado. Tampoco debemos incluir en la comparación el riesgo soberano entendido como la capacidad de pago del Estado, que sí puede ser un riesgo en las exportaciones pero no consta en la relación anterior porque no existe como tal en las operaciones de inversión directa. Sí tenemos en cuenta, en cambio, el riesgo soberano en la inversión directa que está relacionado con las decisiones sobre modificaciones en la regulación y con los incumplimientos de compromisos contractuales que puedan ocasionar pérdidas al inversor. Así pues, el riesgo de ejercicio de la soberanía deberá tratarse en la comparación teniendo en cuenta estas salvedades.

Las modalidades de riesgo país que son exclusivas de la IED deberán ser objeto de otra investigación. En este caso, el estudio no podrá basarse en principios comparativos con el comercio y, por lo tanto, no podrá beneficiarse de la experiencia obtenida en el comercio.

Por último, una vez desarrollados los modelos de valoración de los riesgos comunes y de los riesgos específicos mencionados anteriormente, será pertinente crear un modelo de valoración integrado del riesgo país para la inversión directa. Esta valoración permitirá esclarecer la situación de los mercados y reducirá incertidumbre en la actividad empresarial internacional. 
Dans, Noemi. El riesgo país en la inversión extranjera directa: concepto y modalidades de riesgo.

\section{BIBLIOGRAFÍA}

Berne Union (2012): Yearbook 2012. Ed. Exporta Publishing \& Events Ltd. Londres. Bridgman, P.W. (1959): "The Logic of Modern Physics after Thirty Years", Daedalus. MIT Press. 1959, Vol. 88 n 3, 518-526

Di John, J. (2011): "Failed Status" in Sub - Saharan Africa: A Review of the Literature", Real Instituto Elcano. Ari 5/2011. Madrid.

Diebold, F.X., Doherty, N.A., y Herring, R.J. (2010): The Known, the Unknown and the Unknowable in Financial Risk Management. Measurement and Theory Advancing Practice. Princeton Unviersity Press, Nueva Jersey. 2010, 390 pp.

Doherty, N.A. (2000): Integrated Risk Management: Techniques and Strategies for Reducing Risks. Mac Graw Hill, Nueva York.

Gomory, R. (1995): "The Known, the Unknown and the Unknowable", Scientific American. Junio.

Gordon, K. (2008): "Investment Guarantees”, OECD Investment Policy Perspectives. OECD, Paris.

Herber, M.E. (1992): "Foreign Direct Investment in Country Risk Analysis", International Economic Consultants. Ed Rouledge, Londres y Nueva York.

Holton, G.A. (2004): “Defining Risk”, Financial Analist Journal. Vol. 60, № 6, 19-25

Hyden, G y Agborsangaya-Fiteu, O. (2011): "Diagnostic Tools for Governance in Fragile States: Lessons, Trends and Suggestions". Social Development Departmen. Banco Mundial, Julio 2011.

Iranzo, S. (2008): "Delving into Country Risk", Documentos ocasionales no 08082. Banco de España. Madrid, 2008.

Ibáñez, L.A. (2001): Riesgo Político: Concepto y Práctica. CESCE. Madrid.

James, D. (2004): "Political Risk Insurance after September 11 and the Argentine Crisis: An Underwriter's View from London", International Political Risk Management: The Brave New World. Grupo Banco Mundial, MIGA, Washington DC.

Knight, F. (2006): Risk, Uncertainty and Profit. Ed. Cosimo Classics. 400 pp (1를 edición 1921).

Li, Q. (2006) "Political Violence and Foreign Direct Investment" Regional Economic Integration, Research in Global Strategic Management, Vol. 12, 231-255.

Lloyd's (2011): Annual Report 2010. Society of Lloyd's. Midas Press Plc. Londres

Markovitz, H. (1952): "Portfolio Selection", Journal of Finance. Vol 7. № 1, 77-91.

Meldrum, D. H. (2000): "Country Risk and Foreign Direct Investment”, Business Economics. NABE, National association of Business Economics, Washington.

MIGA, Multilateral Investment Guarantee Agency (2011): World Investment and Political Risk. Grupo Banco Mundial, Washington.

Moosa, I.A. (2002): Foreign Direct Investment: Theory and Practice. Palgrave Macmillan. Nueva York, 2002, 329 pp.

Morel, F. (2010): "Credit Insurance in Support of Internacional Trade. Observations throughout the Crisis" Export Credit Insurance Report. Berne Union. Londres.

OECD/DAC (2008): "Concepts and Dilemas of State Building in Fragile Situations. From Fragility to Resilence", OECD/DAC Discussion paper. París.

OECD (2009): "OECD Studies in Risk Managment. Innovation in Country Risk Management", OECD/DAC Discussion paper. París.

Putzel, J. (2005): "Globalization, Liberalization and Prospects for the State", International Political Science Review. Enero 2005, Vol. 26, ํㅜ1, 5-16. 
Dans, Noemi. El riesgo país en la inversión extranjera directa: concepto y modalidades de riesgo.

Putzel, J. (2006): "War, State Collapse and Reconstruction", Working Paper 1 (2). Crisis States Research Centre.

Ross, M. (2004): "What Do We Know about Natural Resources and Civil War?", Journal of Peace Research, Vol. 41, no. 3, 337-356. Sage Publications.

Sambanis, N. (2002): "A Review of Recent Advances and Future Directions

in the Quantitative Literature on Civil War", Defence and Peace Economics, 13:3, 215-243

Simon J. D. (1989): "Revolution Without Guerrillas", The Rand Corporation Series. Santa Monica, California.

Simon, J.D. (1992): "Political Risk Analysis for International Banks and Multinational Enterprises" Country Risk Analysis. International Economic Consultants, Ed. Rouledge. Londres y N. York.

Vilariño, A. (2001): Turbulencias Financieras y Riesgo de Mercado. Prentice Hall, Madrid, 2001, 300 pp. 
Dans, Noemi. El riesgo país en la inversión extranjera directa: concepto y modalidades de riesgo.

Tabla 1. Eventos que determinan el concepto de riesgo país.

\begin{tabular}{|c|c|c|c|c|c|c|}
\hline Berne Union (2012) & Simon (1992). & Meldrum (2000) & Herber (1992) & MIGA (2011) & OECD (2009) & Iranzo (2008) \\
\hline $\begin{array}{l}\text { Restricciones a la } \\
\text { transferencia de } \\
\text { capitales. }\end{array}$ & $\begin{array}{l}\text { Restricciones a la } \\
\text { transferencia de } \\
\text { capitales. }\end{array}$ & $\begin{array}{l}\text { Restricciones a la } \\
\text { transferencia de } \\
\text { capitales. }\end{array}$ & $\begin{array}{l}\text { Restricciones a la } \\
\text { transferencia de } \\
\text { capitales. }\end{array}$ & $\begin{array}{l}\text { Restricciones a la } \\
\text { transferencia de } \\
\text { capitales. }\end{array}$ & $\begin{array}{l}\text { Restricciones a la } \\
\text { transferencia de } \\
\text { capitales. }\end{array}$ & $\begin{array}{l}\text { Restricciones a la } \\
\text { transferencia de } \\
\text { capitales. }\end{array}$ \\
\hline $\begin{array}{l}\text { Limitaciones a la } \\
\text { convertibilidad. }\end{array}$ & $\begin{array}{l}\text { Limitaciones a la } \\
\text { convertibilidad. }\end{array}$ & $\begin{array}{l}\text { Limitaciones a la } \\
\text { convertibilidad. }\end{array}$ & $\begin{array}{l}\text { Limitaciones a la } \\
\text { convertibilidad. }\end{array}$ & $\begin{array}{l}\text { Limitaciones a la } \\
\text { convertibilidad. }\end{array}$ & $\begin{array}{l}\text { Limitaciones a la } \\
\text { convertibilidad. }\end{array}$ & $\begin{array}{l}\text { Limitaciones a la } \\
\text { convertibilidad. }\end{array}$ \\
\hline $\begin{array}{l}\text { Nacionalización, } \\
\text { Expropiación y } \\
\text { Confiscación }\end{array}$ & $\begin{array}{l}\text { Nacionalización, } \\
\text { Expropiación y } \\
\text { Confiscación }\end{array}$ & $\begin{array}{l}\text { Nacionalización, } \\
\text { Expropiación y } \\
\text { Confiscación }\end{array}$ & $\begin{array}{l}\text { Nacionalización, } \\
\text { Expropiación y } \\
\text { Confiscación }\end{array}$ & $\begin{array}{l}\text { Nacionalización, } \\
\text { Expropiación y } \\
\text { Confiscación }\end{array}$ & $\begin{array}{l}\text { Nacionalización, } \\
\text { Expropiación y } \\
\text { Confiscación }\end{array}$ & $\begin{array}{l}\text { Nacionalización, } \\
\text { Expropiación y } \\
\text { Confiscación }\end{array}$ \\
\hline Violencia Política & Violencia Política & $\begin{array}{c}\text { Guerra y Violencia } \\
\text { Política }\end{array}$ & $\begin{array}{c}\text { Guerra y Violencia } \\
\text { Política. Disputas } \\
\text { territoriales. }\end{array}$ & $\begin{array}{l}\text { Guerra, terrorismo, } \\
\text { inestabilidad social. }\end{array}$ & $\begin{array}{l}\text { Guerra y violencia } \\
\text { política }\end{array}$ & $\begin{array}{c}\text { Guerra y violencia } \\
\text { política }\end{array}$ \\
\hline $\begin{array}{l}\text { Incumplimiento de } \\
\text { contratos o de } \\
\text { préstamos. }\end{array}$ & $\begin{array}{l}\text { Cambios en la } \\
\text { regulación. } \\
\text { Ruptura de } \\
\text { compromisos. }\end{array}$ & $\begin{array}{c}\text { Soberano: } \\
\text { Cambios en la } \\
\text { regulación. } \\
\text { Voluntad de pago. } \\
\text { Relación bilateral } \\
\text { Localización. } \\
\text { Riesgo de Cambio }\end{array}$ & $\begin{array}{l}\text { Cambios en la } \\
\text { regulación. } \\
\text { Incumplimiento } \\
\text { contractual. } \\
\text { Política Económica. }\end{array}$ & $\begin{array}{l}\text { Incumplimiento } \\
\text { de compromisos, } \\
\text { ruptura de } \\
\text { contratos, cambios } \\
\text { adversos en la } \\
\text { regulación. }\end{array}$ & $\begin{array}{l}\text { Incumplimiento de } \\
\text { obligaciones } \\
\text { (deudas, } \\
\text { contractuales) }\end{array}$ & $\begin{array}{l}\text { Incumplimiento de } \\
\text { compromisos. }\end{array}$ \\
\hline
\end{tabular}

Fuente: elaboración propia. 